\title{
Guidance Document: Heart Failure Toolbox
}

\section{KARGER}

E-Mail karger@karger.com www.karger.com/crd
(2) 2019 The Author(s)

Published by S. Karger AG, Basel

Karger

Open access

This article is licensed under the Creative Commons Attribution 4.0 International License (CC BY) (http://www.karger.com/Services/ OpenAccessLicense). Usage, derivative works and distribution are permitted provided that proper credit is given to the author and the 
Heart Failure $\checkmark$ TOOLBOX

Guidance
document
Heart Failure Toolbox 

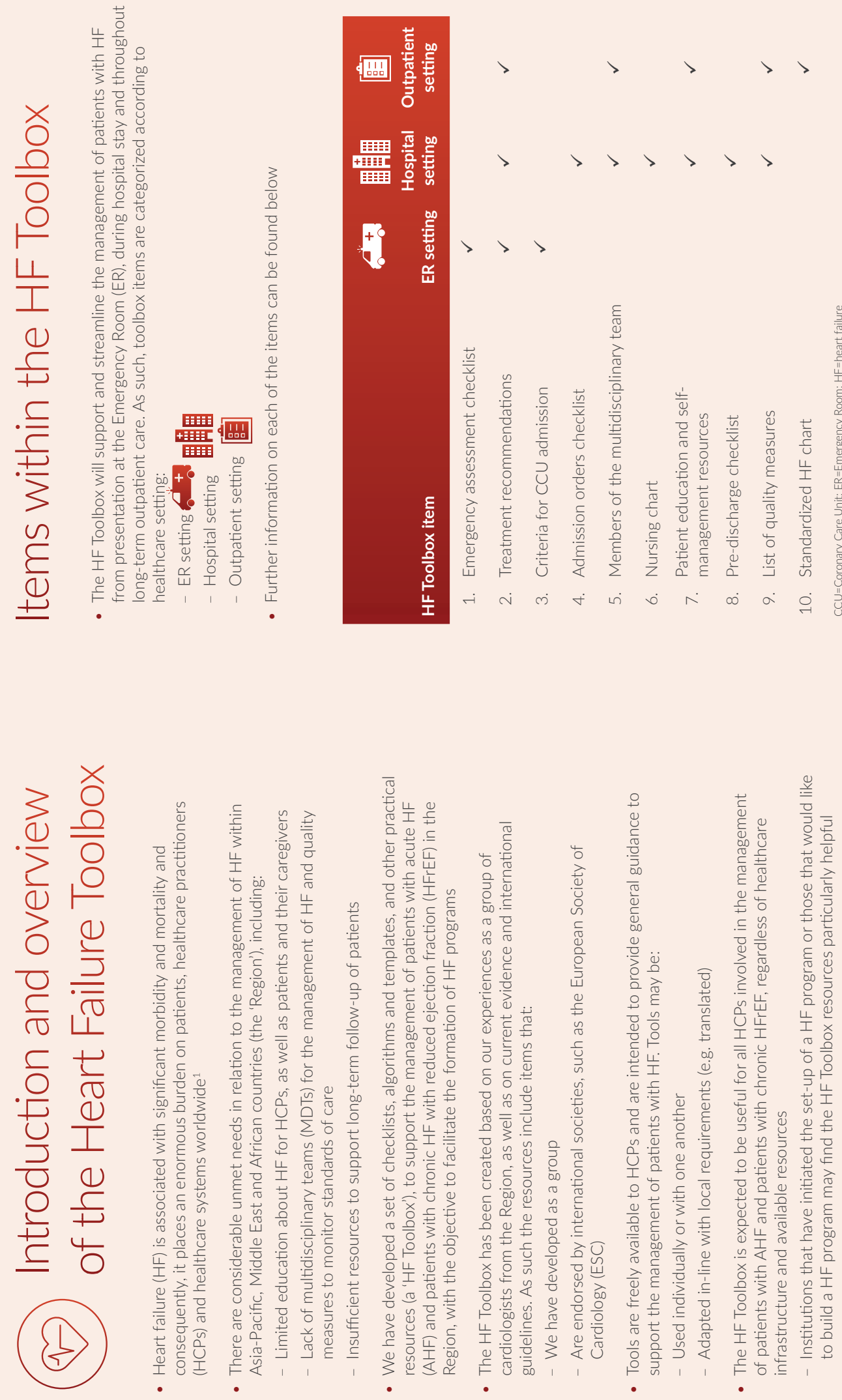

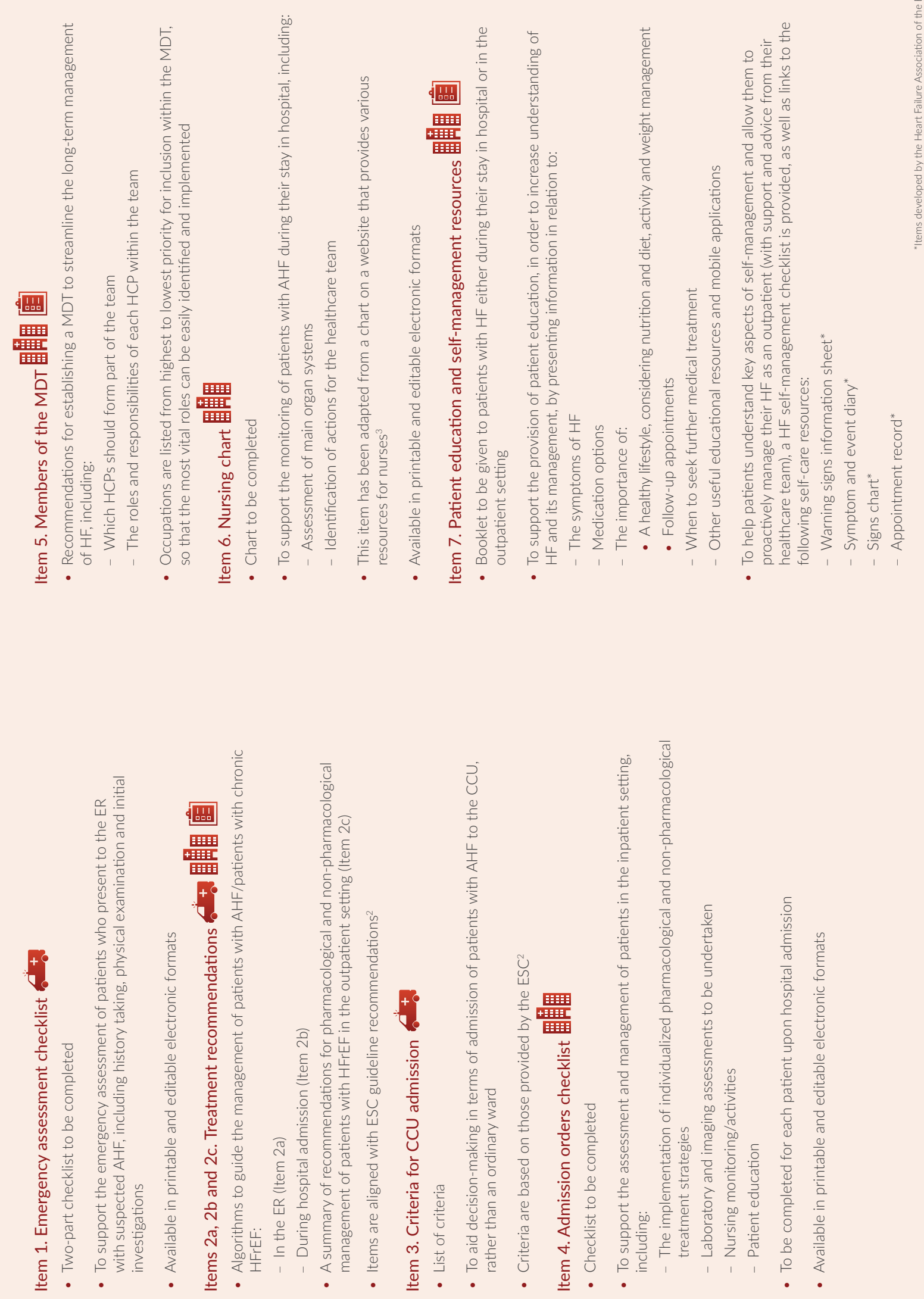

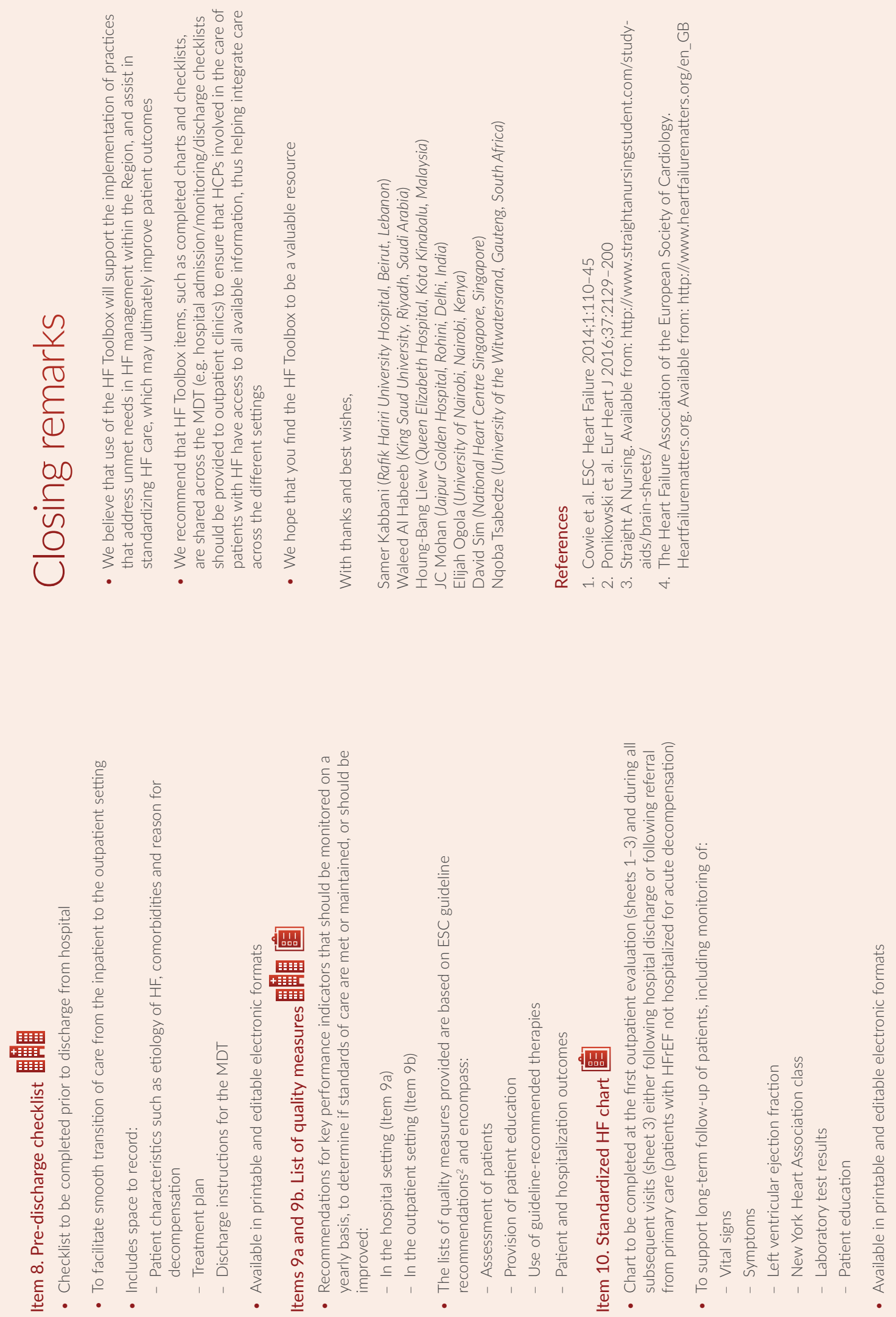


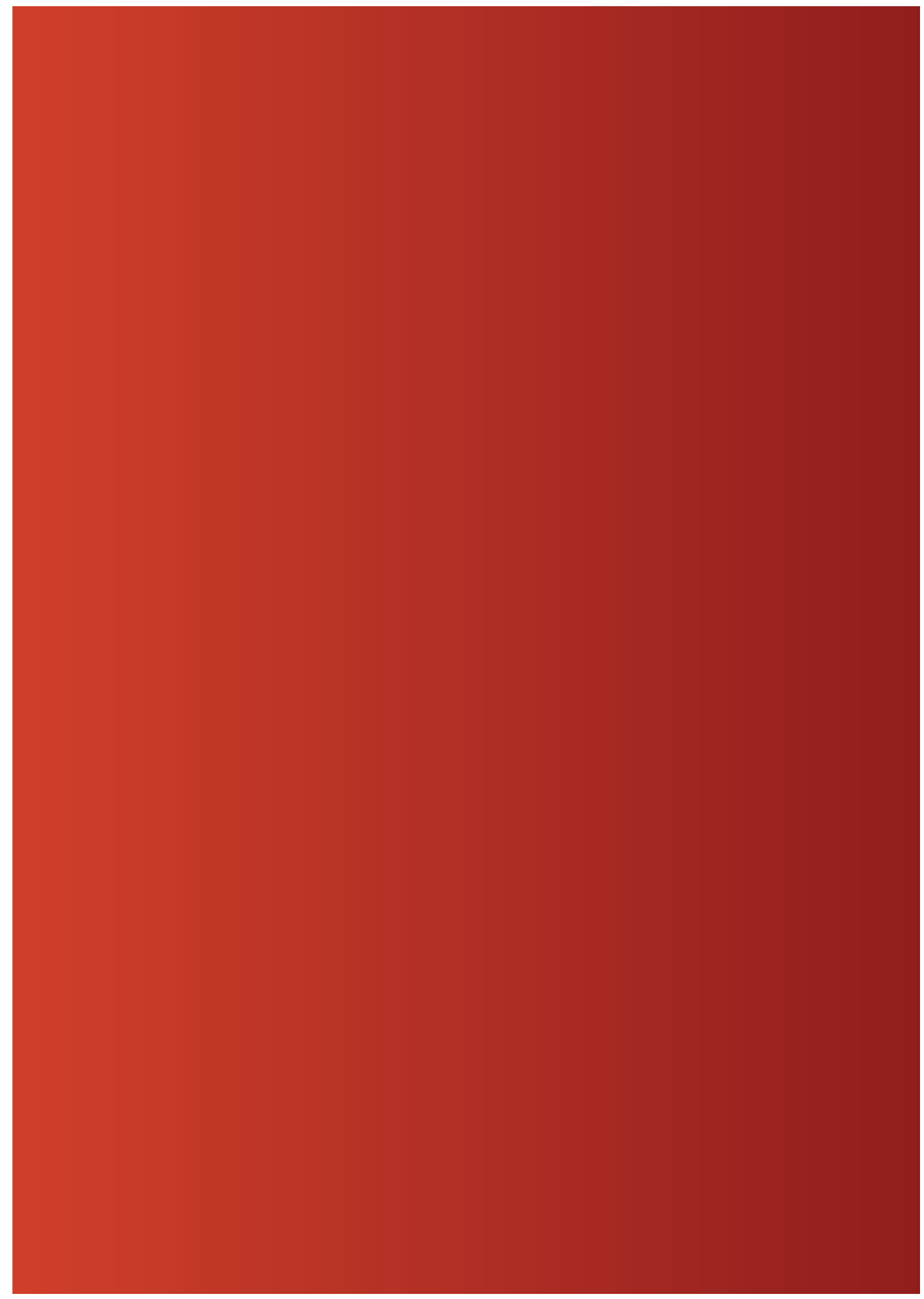

